\title{
Techno-economic evaluation of an ontology-based nurse call system via discrete event simulations
}

\author{
Frederic Vannieuwenborg, Femke Ongenae, Pieter Demyttenaere, Laurens Van Poucke, Jan Van Ooteghem, Stijn \\ Verstichel, Sofie Verbrugge, Didier Colle, Filip De Turck, Mario Pickavet \\ Dept. of Information Technology (INTEC) \\ Ghent University - iMinds \\ Ghent, Belgium
}

[frederic.vannieuwenborg, femke.ongenae, jan.vanooteghem, stijn.verstichel, sofie.verbrugge, didier.colle, filip.deturck,
mario.pickavet]@intec.ugent.be
[pieterp.demyttenaere, laurensr.vanpoucke]@ugent.be

\begin{abstract}
Current nurse call systems hinder the efficiency of nurses as the systems are not aware of the type of requested help and the context in which their help is required. To tackle these issues, we have developed an ontology-based nurse call system that automatically takes the patients' and caregivers' profiles and context into account when assigning calls to nurses by modelling this information in an ontology, i.e., a formal domain model. For example, current tasks of the nurses and trust relationship with patients are considered while allocating calls to caregivers. Focus is not only on creating a higher quality patient care, but also on distributing the workload more evenly over all caregivers. However, not in all hospital departments such a smart nurse call system will have a significant impact, e.g., geriatric versus emergency care. To gain insights into the total impact of a smart nurse call system, a dedicated discrete event simulation (DES) model is presented that tests its performance. Based on realistic nurse call logs and information gathered at representative hospital departments through interviews and observations, the simulation model allows optimizing decisions, modelled as rules based on the information captured in the ontology, to allocate calls to the best suited nurse. Several scenarios with a varying number of calls, staff members, etc. are tested to be able to define the effectiveness and the (dis)advantages of the ontology-based system with respect to the current one. In conclusion, recommendations are made towards improving the currently employed nurse call systems in hospitals.
\end{abstract}

Keywords-Nurse call system; Ontology; Key Performance Indicators (KPIs); Discrete Event Simulation (DES); eHealth

\section{INTRODUCTION}

Due to the persistent pressure on the financial resources of hospitals and the care sector in general, these parties seek to optimize budgets and cut costs where possible [1]. Consequently, they aim to increase the work efficiency of the nurses. However in reality this means doing more with the same staff, doing the same with a smaller staff or fragmenting the tasks for several care providing profiles. The latter means that new task and job profiles are identified and introduced next to the current tasks of nurses (e.g., logistic personnel that can take care for the hotel service requests and tasks that do not require medical competences, etc.). The workload on the staff and the required competences of nurses continue to rise. In order to preserve the time for, and quality of care, efficiency improvements need to be sought in their work methods and non-care related tasks in particular.

Current nurse call systems are not optimal for work efficiency since they do not provide context information on the particular nature of the call. This means that sometimes more than one nurse will go to a room and that there is no prioritization of the calls possible. Every call can be urgent and should be treated with the same effort. But in general there exist many different types of calls such as one for providing hotel services, e.g. getting a bottle of water, or pure care related tasks, e.g. giving medication. Also depending on person characteristics, a patient can call very often for nonurgent matters, while others may never call, even if it's very urgent.

The nurse call system, developed in the Accio Project [2], is an ontology-based nurse call system that reasons on available context information such as distance to the calling patient, type of call, personal and therapeutic relationship with the patient, the current tasks of the nurses, etc. to alert the best suited staff member. The goal of this ontology-based nurse call system is to lower the workload by dividing it more evenly over all nurses, to lower the waiting times and prioritize urgent calls over less urgent ones [2]. The overall aim is not to interrupt the nursing staff while they perform difficult tasks.

\section{RESEARCH OBJECTIVE}

The goal of this research is to evaluate the impact and the effects for the nursing staff and the patients when implementing an ontology-based nurse call system that takes the context of the call and profiles of the staff and patients into account. The total impact of such a system depends heavily on the type of care department and setting. Consequently, it is expected that not all care departments will benefit equally from installing such a system.

To gain insights in the key-parameters that determine the impact of an ontology-based nurse call system a discrete event 
simulation model (DES) is built which allows comparing the potential impact of such a system with a traditional nurse call system that does not take into account context parameters.

\section{METHODOLOGY}

The DES model, developed to determine the impact of an ontology-based nurse call system and the adjustments to its rule set, is a result of a three step process: 1) Translating the ontology-based rule set to a format that can be handled by the DES model, 2) Setting up the simulation model based on the rule set and 3) analysing the simulation results. Fig. 1 shows a schematic overview of this methodology.

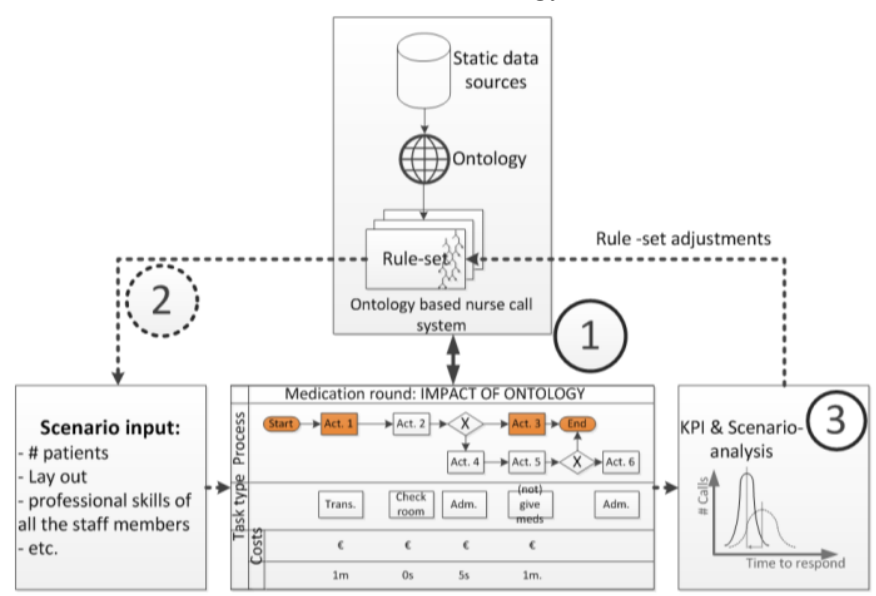

Fig. 1. Schematic overview of the methodology

\section{A. Step 1: Translating the rule set}

A definition of an ontology is given by Gruber T. [5]: "An ontology is a specification of a conceptualization in the context of knowledge description". This means that ontologies describe concepts, relations between those concepts and characteristics in a certain domain of interest. An example of a relationship in the ontology-based nurse call system is the degree of trust between patient and caregiver. For this research, the Ambient-Aware Continuous Care Ontology was used [13]. On top of the ontology a rule set is implemented that encodes the decisions that the system needs to make in a particular situation. Generic reasoning software, i.e., Pellet [14], is then used to process the ontology and accompanying rules in order to, e.g., determine the status of a caregiver or assign a call to a staff member. Excerpts of the decision process and accompanying rules can be found in [13].

Executives, such as the head nurse or the head of a department, should be able to make any adjustments to the rule set so that they are able to refine the nurse call assignment algorithm to their particular department. However, before introducing the new rules or definitions into the department, they need to evaluate whether these adjustments will have a positive impact. To ease the evaluation, rules should be interchanged automatically between the ontology and the simulation software.
Currently, the ontology in the nurse call system is implemented in the Web Ontology Language (OWL). [3] The rules, which use the information in the ontology, are implemented in Jena [11]. However, to make the translation process more generic and thus applicable to a wide range of (semantic) rule languages, it was opted to first translate the Jena Rules to the Rule Interchange Format (RIF) [12]. RIF is a recently developed format that is designed to exchange rules that are expressed in different rule languages. As such, most rule languages can easily be translated to RIF. This makes it an ideal starting point.

\section{B. Step 2: Developing the simulation model of the ontology based nurse call system}

For the simulations it is examined which software would be best for testing the nurse call system. Out of different discrete event simulation software packages such as TIBCO Business events [15], Arena [8], Flexism [7], etc. eventually FlexSim is chosen because of it graphical interface, well developed parameter dashboard and its ability to define the rule set in external files.

Input data is created in Microsoft Excel and consists of all calls and the different task rounds, with their respective labels, that will be launched during the simulation. Every aspect of the created data is based on anonymized real-life data from Televic [9], a Belgian nurse call system producer and integrator. The data was analysed for patterns in the arrival times of calls. As a result, each day was divided in several time periods in which calls have a predefined chance to occur. The distribution of the call types, e.g., calls for hotel or care services, urgent medical calls, etc., was based on a study by Meade, et al. [16].

\section{Step 3: Scenario analysis}

Eight different scenarios are investigated. First, a setting with the traditional nurse call system, 'Traditional', and one with the ontology-based nurse call system, 'Accio', are analysed. Second, three scenarios are used to test the effects of a certain decision on the effectiveness of the ontology. And at last, three new adjustments to the rule set are introduced to try to improve the performance of the nurse call system. The scenarios are described below in Table 1 .

Table 1. Overview of the different scenarios

\begin{tabular}{|l|l|}
\hline Scenario & Description \\
\hline 1. Traditional & The traditional installed nurse call system calls \\
system & all the nurses within the department that are \\
(3 nurses, 1 & linked to the room where the call is made and \\
logistic & after a while reminds them again of the call \\
assistant, 1 & after it is detected that nobody answered the \\
head nurse) & first call. This is the reference scenario. \\
\hline $\begin{array}{l}\text { 2. Accio system } \\
\text { (2 nurses, }\end{array}$ & $\begin{array}{l}\text { The scenario in which the ontology- based } \\
\text { lcarer, } 1\end{array}$ \\
logistic & nurse call system is installed. It takes into \\
assistant, 1 & account the context parameters in which the \\
head nurse) & call was made in order to inform the most \\
\end{tabular}




\begin{tabular}{|c|c|}
\hline & $\begin{array}{l}\text { differs from the staffing in the traditional } \\
\text { scenario. One nurse was replaced by a } \\
\text { caregiver without all the medical competences } \\
\text { of a nurse. }\end{array}$ \\
\hline $\begin{array}{l}\text { 3. Effect 1: } \\
\text { Medical staff } \\
\text { (3 nurses, } 1 \\
\text { logistic } \\
\text { assistant, } 1 \\
\text { head nurse) }\end{array}$ & $\begin{array}{l}\text { In this scenario, the impact is evaluated if the } \\
\text { complete staff has medical competences. This } \\
\text { means that every caregiver can respond to } \\
\text { every type of a call. Since a traditional system } \\
\text { does not know which type of call was meant, it } \\
\text { cannot differentiate on competences like the } \\
\text { Accio system can, e.g. medical tasks can be } \\
\text { performed by medical personnel only and hotel } \\
\text { task should be performed by logistic personnel } \\
\text { but can also be done by medical personnel. For } \\
\text { more information see [6]. }\end{array}$ \\
\hline $\begin{array}{l}\text { 4. Effect 2: } \\
\text { Strict } \\
\text { competences } \\
\text { (Same staff as } \\
\text { Accio scen.) }\end{array}$ & $\begin{array}{l}\text { In this scenario, the impact is evaluated of the } \\
\text { fact that not all caregivers have the required } \\
\text { qualifications/competences to respond to } \\
\text { certain calls, e.g. logistic personnel versus } \\
\text { medical personnel. }\end{array}$ \\
\hline $\begin{array}{l}\text { 5. Effect 3: } \\
\text { Incorporation } \\
\text { of trust } \\
\text { relationship } \\
\text { (Same staff as } \\
\text { Accio scen.) }\end{array}$ & $\begin{array}{l}\text { This scenario evaluates the impact of not } \\
\text { respecting the trust relationship, in the sense of } \\
\text { prioritizing staff members with a trust relation } \\
\text { with the patient above other staff members, as } \\
\text { there are doubts during the development to } \\
\text { incorporate these trust relationships into the } \\
\text { rule set and on the practical implementation of } \\
\text { this constraint in reality. }\end{array}$ \\
\hline $\begin{array}{l}\text { 6. Adjustment } \\
1 \text { : Adding new } \\
\text { respond } \\
\text { statuses } \\
\text { (Same staff as } \\
\text { Accio scen.) }\end{array}$ & $\begin{array}{l}\text { In this scenario, a first change to the existing } \\
\text { Accio system is analysed. If the Accio system } \\
\text { detects that multiple nurses can respond to a } \\
\text { call, the system will call all of them. Because } \\
\text { the system will queue the call for the most } \\
\text { appropriate nurse, the system should be aware } \\
\text { of the fact if there are already calls waiting to } \\
\text { be responded before adding new ones, } \\
\text { otherwise waiting times would become } \\
\text { unacceptable. }\end{array}$ \\
\hline $\begin{array}{l}\text { 7. Adjustment } \\
\text { 2: Workload } \\
\text { balancing } \\
\text { (Same staff as } \\
\text { Accio) }\end{array}$ & $\begin{array}{l}\text { In this scenario, a second adjustment to the } \\
\text { existing rule set of the Accio system is } \\
\text { analysed. The system will direct the call to an } \\
\text { appropriate person with the least amount } \\
\text { previous answered calls. Doing so, the system } \\
\text { tries to distribute the workload resulting from } \\
\text { patient calls evenly over the complete care } \\
\text { staff. }\end{array}$ \\
\hline $\begin{array}{l}\text { 8. Adjustment } \\
\text { 3: Prioritizing } \\
\text { status above } \\
\text { trust } \\
\text { relationship } \\
\text { (Same staff as } \\
\text { Accio) }\end{array}$ & $\begin{array}{l}\text { In a last scenario, two existing decision rules } \\
\text { are interchanged in order to change their } \\
\text { priority. The constraining rule on trust } \\
\text { relationship is swapped places with the rule } \\
\text { that respects the current task of the staff } \\
\text { members. As such, the current task of the } \\
\text { caregivers is taken more into account than the } \\
\text { trust relationship with the patient when } \\
\text { assigning calls. This adjustment is } \\
\text { implemented because simulation results } \\
\text { showed that the decision tree is too selective on } \\
\text { the trust relationship and could not differentiate } \\
\text { on the current task anymore. }\end{array}$ \\
\hline
\end{tabular}

Nine different Key Performance Indicators (KPIs) are considered during the analysis.

\begin{tabular}{|l|}
\hline Key performance indicators \\
\hline 1. Distance per shift. As the Accio nurse call system considers the \\
location of the caregivers and the patients, it could be expected \\
that the caregivers have to walk less to perform the same work. \\
\hline 2. Balancing the workload: in the simulations it will be inspected \\
whether the system succeeds in balancing the workload in a better \\
way. \\
\hline 3. Average waiting time: Average time until a call is answered by \\
a nurse or other caregiver. \\
\hline 4. Maximum waiting time: Maximum time until a call is answered \\
by a nurse or other caregiver. \\
\hline 5. Required competences: Does the selected caregivers have the \\
required competences to fulfil the intervention? \\
\hline 6. Trust relationship with the patient: Did the ontology respect \\
the trust relationship between the patient and the caregiver? \\
\hline 7. Number of simultaneous selected caregivers per call. \\
\hline 8. Number of disturbing calls: Can the ontology prevent \\
disturbing the nurse while performing a hard task? \\
\hline 9. Number of redirections per call: being the amount of times a \\
call cannot be responded by the addressed caregiver and therefore \\
is redirected to another colleague. \\
\hline
\end{tabular}

\section{RESULTS}

All eight scenarios are tested in two different departments. Department 1 represents a small department with a small number of caregivers and calls per week (normal staff: 3 nurses, 1 head nurse, and 1 logistic assistant; 18 patients; nbr. of calls: $40-280$ calls per week). Department 2 is bigger in size and has a higher average number of calls (normal staff: 5 nurses, 1 head nurse, and 1 logistic assistant; 26 patients; nbr. of calls: $600-800$ calls per week). More information on the particular departments can be found in [9].

First, a comparative analysis on the 'Accio' versus the 'Traditional' scenario is performed for both departments. Increasing the number of calls per week has a deteriorating effect on all KPIs. For example the average- and maximum waiting times rise for both departments as illustrated for the average waiting time in department 1 in Fig. 2.

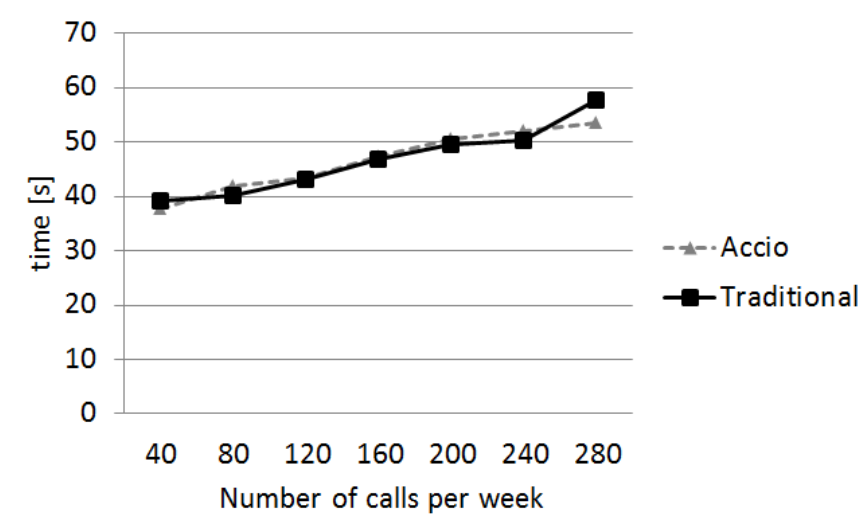

Fig. 2. Average waiting time in function of the number of calls per week ('Accio' on department 1)

As can be seen, there is no impact of an ontology-based nurse call system on the average waiting time compared to the 
traditional system in this particular department. The variance on the average waiting time on the other hand is reduced compared to the traditional system. On top of that, in the Accio scenario, one nurse is replaced by a caregiver without the medical competences of a nurse. This could reduce the staffing costs of departments.

Next, the fraction of answered calls as a function of the waiting time is analysed. On Fig. 3 a significant difference can be seen between the Traditional and Accio scenario. For the Traditional scenario, two peaks arise. One at about 20 seconds - immediate answer - and one at 140 seconds -after ignoring a first call, e.g., because the nurse was busy with another patient, the system will send a reminder call to the nurses. This will prompt the nurses to answer the call then.

For the Accio scenario, these two peaks were scattered over a range of 20 and 120 seconds. These findings are a result of the possibility of redirecting a call to a colleague. Redirecting gives a caregiver the possibility to immediately forward a colleague when he/she is currently too busy to handle it. These findings indicate that if the nurse knows the context of a call, that person can better organize his responding actions to it instead of answering immediately.

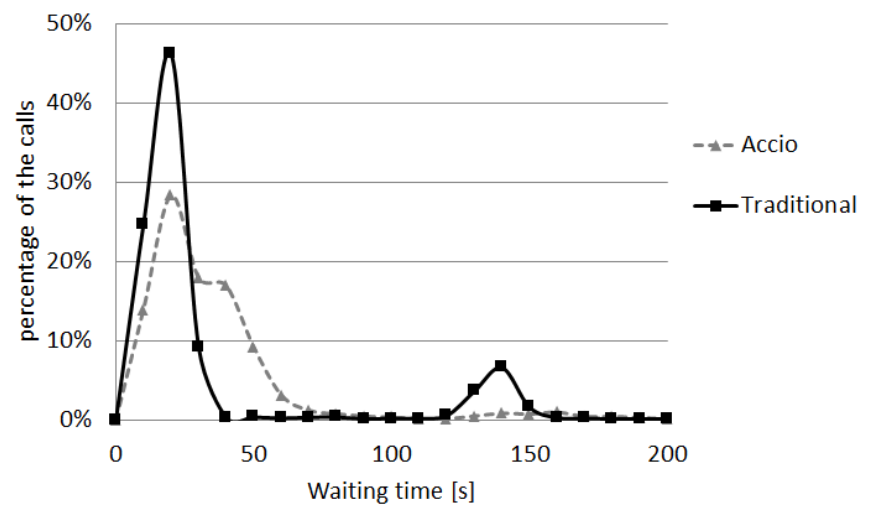

Fig. 3. Percentage of calls in function of the waiting time (Accio vs Traditional on department 1 )

Scenario 3: 'Effect 1 ' is analysed mainly to evaluate the difference in work load distribution between the Traditional and the Accio nurse call system (Effectl and the Traditional scenario have the same staff members.). Fixed nursing rounds, e.g., check-up tours, are, together with answering patient calls, important factors that influence the work load of a nurse. Comparing 'Effect 1' to 'Accio', does not show many differences. This gives executives the opportunity to hire lower educated and thus less expensive employees without lowering the quality of care.

Another important KPI is the percentage of calls that disturbs a caregiver. Disturbing a nurse while performing a difficult task, e.g., medication preparation, significantly increases the risk on errors [10]. Both departments show different results for this KPI because of the different number of employees. In department 2, 'Accio' has a lower percentage of disturbing calls than 'Traditional'. This percentage is higher in department 1 since the smaller number of employees prevented the system from selecting a nurse that is not occupied. This is mainly caused by the fact that the system acts too conservative on the trust relationship between caregivers and patients. This phenomenon is affirmed in 'Effect 3' (see Fig. 4), where the system does not incorporate the trust relationship and therefore has a larger pool of employees to allocate calls to.

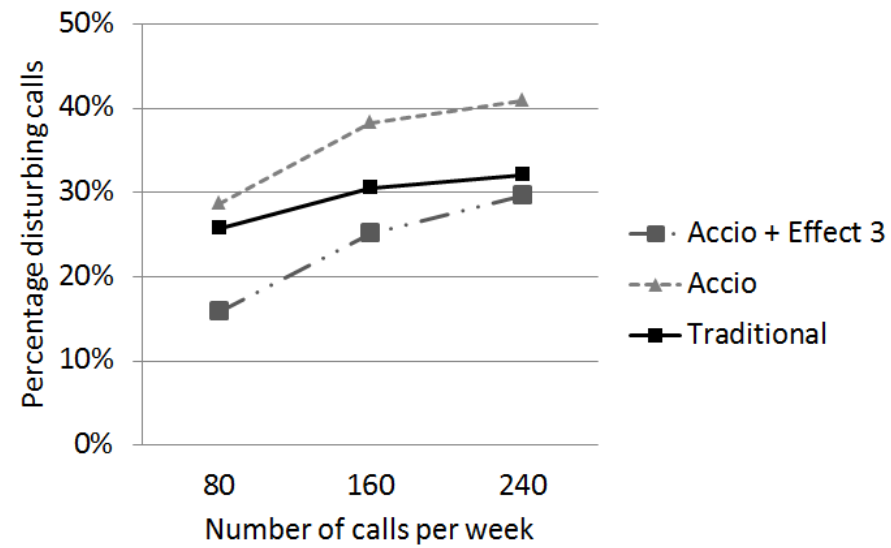

Fig. 4. Percentage of disturbing calls ('Accio' vs 'Traditional' vs 'Effect 3' on department 1)

'Effect 3' has, next to the lower percentage of disturbing calls, also a drawback. As the system differentiates less on the trust relationship, more caregivers are selected per call resulting in a larger average covered distance per shift. This is illustrated in Fig. 5 for the average distance for all caregivers during the evening shift on department 2 . Thus relaxing this constraint means that more nurses start walking to the room of the patient. This effect can be remediated when the nurses get more and more acquainted with the system and know that they should acknowledge before starting walking to the patient. In this way all the other nurses see that the call is already assigned to a person, so no action is required from them.

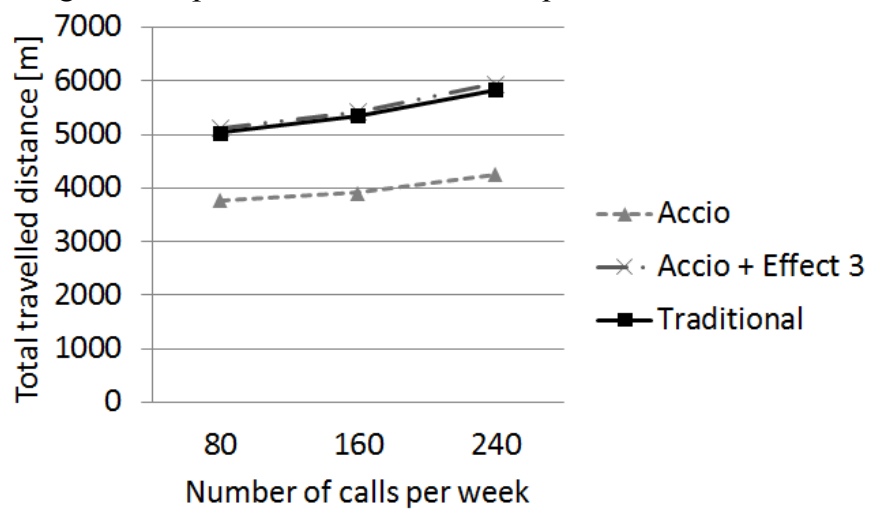

Fig. 5. Total average covered distance of all caregivers in the evening shift ('Accio' vs 'Effect 3' on Department 2)

Scenario 6: 'Adjustment 1' is a first modification to the rule set to prevent a caregiver from having a large queue of calls waiting. Occasionally, it happens that a caregiver is on his way to a patient to answer his call and at that moment receives a new call from another patient because he is currently not busy with a task. With 'Adjustment 1' this situation can no longer 
occur. It is expected that maximum waiting times would drop. The model indeed indicates shorter waiting times as illustrated in Fig. 6.

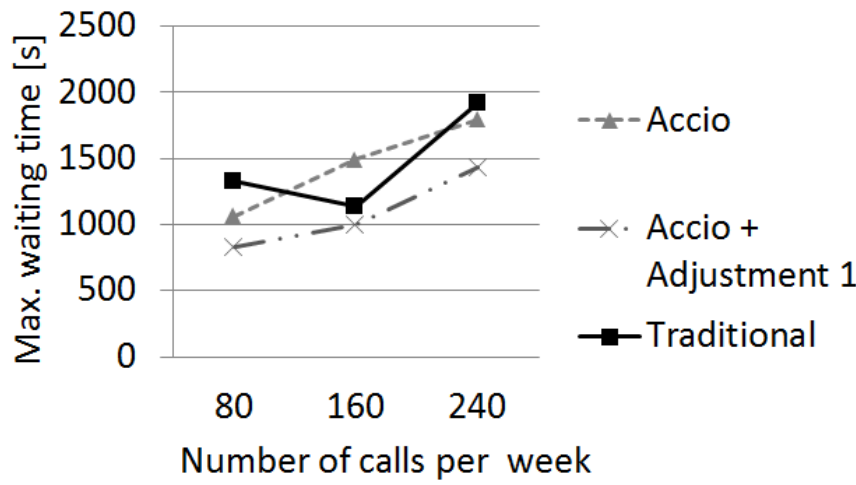

Fig. 6. Maximum waiting time in function of the number of calls per week ('Accio' vs 'Adjustment 1' on department 1)

The modification to the existing rule set that gives the best results for both departments is 'Adjustment 3'. This is the one in which the order of the decisive blocks in the rule set is changed. Now, the ontology first checks the status of the nurses before checking their trust relationship with the patient. The scenario strongly decreases the percentage disturbing calls, because the system will first direct the call to nurses who are not busy with hard tasks. This is illustrated in Fig. 7.

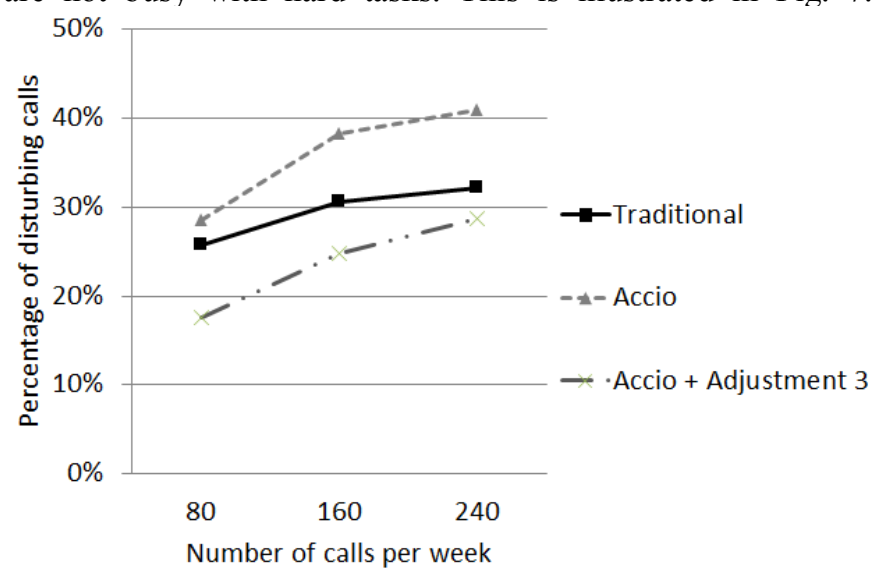

Fig. 7. Percentage disturbing calls ('Accio' vs 'Adjustment 3' on department 1)

This has several positive effects such as lower average and maximum waiting times and a lower number of redirected calls. However, as the system cannot take into account the trust relationship as well for the Accio scenario does, this new rule set leads to a higher percentage of confidence breaks, i.e., the call is handled by a caregiver with whom the patient does not have a very good trust relationship. The difference in percentages is illustrated in Fig. 8. It is up to the executives to choose what is most important for them, the trust relationships, or the disturbing calls.

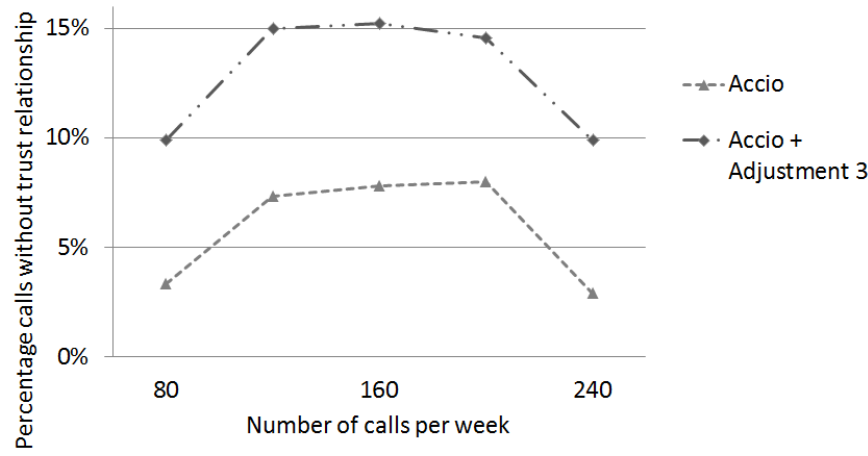

Fig. 8. Percentage of calls for which there was no trust relationship between caregiver and patient ('Accio' vs 'Adjustment 3' on Department 1)

\section{CONCLUSIONS}

In this paper a methodology and results are presented of a discrete event simulation model of an ontology based nurse call system.

The results mainly shows that trade-offs will have to be made when executives choose the best rule set for their department. When one of the decisive rules becomes too discriminating, the system will not be able to properly use one of the next. One example has been given with the 'Trust Relationship' and the 'Current task' blocks. A lower percentage of breaks in the trust relationship will result in a higher percentage of disturbing calls and vice versa. Secondly, the results make clear that an ontology-based nurse call system can be beneficial for the work load, processes and atmosphere.

Lastly, it is recommended that, when the Accio nurse call system is introduced, it should be easy for executives to make adjustments to the rule set of the system (via a dashboard of KPI's). In this manner, they could impose their own accents on the system so that their department operates exactly the way they want it to. The developed discrete event simulation model and automatic translation tool could help in achieving this goal.

\section{ACKNOWLEDGMENT}

This research was based on the results and systems developed within the iMinds Project ACCIO [2]. This project was co-funded by IWT, iMinds and the following partners: Televic NV, Boone NV, Dominiek Savio Instituut and In-Ham. This research work was partially supported by the Concerted Research Actions grant for the research project: "High Potential Entrepreneurship and entrepreneurial value creation: context influences, context interactions and context extension" (project code 01G03011) from the Ghent University and the NBB, National Bank Belgium. F. Vannieuwenborg also has received funding from the Agency for Innovation by Science and Technology in Flanders (IWT) through his PhD grant.

\section{REFERENCES}

[1] B. \&. R. I. Haeck, "Waarom uw ziekenhuis vecht om te overleven," De Tijd, pp. 4-5, 19 Oktober 2013

[2] iMinds, „Accio - Ambient aware provisioning of continuous care for intra-muros organization," [Online]. Available: http://www.iminds.be/nl/projecten/2014/03/04/accio. [Accessed on 3 October 2013]. 
[3] McGuinnes, D. L. \& Van Harmelen, F. (2004). OWL Web Ontology Language overview. W3C Recommendation. Available at:

[4] http://www.w3.org/TR/2004/REC-owl-features-20040210. "W3C: World Wide Web Consortium," [Online]. Available: http://www.w3.org.

[5] T. R. Gruber, "Toward principles for the design of ontologies used for knowledge sharing," International Journal HumanComputer Studies, vol. 43, nr. 5-6, pp. 907-928, 1995.

[6] Ongenae F, Duysburgh P, Verstraete M, Sulmon N, Bleumers L, Jacobs A, Ackaert A, De Zutter S, Verstichel S, De Turck F: User-driven design of a context-aware application: an ambientintelligent nurse call system. In Proceedings of the UserCentered Design of Pervasive Healthcare Applications Workshop (U-CDPHA) of the 6th International Conference on Pervasive Computing Technologies for healthcare (PervasiveHealth): 21-24 May 2012; San Diego, CA, USA, Piscataway, NJ, USA: IEEE; 2012:6.

[7] FlexSim Software Products (FSP), "FlexSim," [Online]. Available: www.flexsim.com. [Accessed on 16 Oktober 2013].

[8] Rockwell Automation, "Arena Simulation Software," Rockwell, [online]. Available: www.arenasimulation.com [Accessed on 23 October 2014].

[9] Ongenae, F., D. Myny, et al. (2011). "An ontology-based nurse call management system (oNCS) with probabilistic priority assessment." BMC Health Services Research 11(1): 26.

[10] Westbrook, J. I., A. Woods, et al. (2010). "Association of interruptions with an increased risk and severity of medication administration errors." Archives of Internal medicine 170(8): 683-690.

[11] Carroll JJ, Dickinson I, Dollin C, Reynolds D, Seaborne A, Wilkinson K: Jena: implementing the semantic web recommendations. In Proceediungs of the 13th international Conference on World Wide Web (WWW) - Alternate track papers \& posters: May 17-20 2004; New York, NY, USA. Edited by Feldman S, Uretsky M, Najork M, Wills C, New York, NY, USA: ACM; 2004:74 \{83.

[12] Kifer, M. \& Boley, H., RIF Overview (Second Edition), W3C Working Group Note, 5 February 2013 , http://www.w3.org/TR/rif-overview/

[13] Ongenae F, Bleumers L, Sulmon N, Verstraete M, Jacobs A, Van Gils M, Ackaert A, De Zutter S, Verhoeve P, De Turck F: Participatory Design of a Continuous Care Ontology: Towards a User-Driven Ontology Engineering Methodology. In Proceedings of the International Conference on Knowledge Engineering and Ontology Development (KEOD): 26-29 October 2011; Paris, France. Edited by Filipe J, Dietz JLG, ScitePress Digital Library; 2011:81-90.

[14] Sirin E, Parsia B, Grau BC, Kalyanpur A, Katz Y: Pellet: A Practical OWL-DL Reasoner. Journal of Web semantics: Science, Services and Agents on the World Wide Web 2007, $5(2): 51-53$

[15] TIBCO Software Inc., „TIBCO” [online]. Available at: www.tibco.nl [Accessed on 23 October 2014]

[16] Meade CM, Bursell AL, Ketelsen L: Effects of Nursing Rounds on Patients' Call Light Use, Satisfaction and Safety. AM J NURS 2006, 106(9):58-70. 